\title{
Missivas pessoais, memória e arquivo: Uma reflexão
}

Personal missives, memory

and archive: A reflexion

Moema Rodrigues Brandão Mendes

UniAcademia/CES/JF, FCRB/RJ

Bárbara Barros Gonçalves Pereira Nolasco UniAcademia/CES/JF 
Este artigo centra-se na correspondência como elemento de resgate e preservação da memória cultural e literária de Mário Matos e Gilberto de Alencar. Este lote de cartas está centrado nas redes de sociabilidade que se mantiveram por meio de treze cartas enviadas por Matos entre 1945 e 1957. Busca-se, com esta reflexão, promover a imagem dos escritores mineiros, conservar vivas as suas obras e divulgar seus posicionamentos socioculturais a fim de alcançar uma significativa repercussão de suas produções junto ao público leitor. Este material epistolográfico encontra-se sob a custódia do Museu de Arte Murilo Mendes - MAMM, administrado pela Universidade Federal de Juiz de Fora (UFJF), em Minas Gerais, depositada no Acervo da Família Alencar, no Fundo arquivístico do titular Gilberto de Alencar.

Palavras-chave: Mario Matos; Gilberto de Alencar; memória; correspondência

\section{Abstract}

This article focuses on correspondence as an element to rescue and preserve the cultural and literary memory of Mário Matos and Gilberto de Alencar. This batch of letters is centered on the sociability networks that they maintained through 13 letters sent by Matos between 1945 and 1957. With this reflection, we seek to promote the image of Minas Gerais writers, to keep their works alive and to disseminate their sociocultural positions in order to achieve a significant repercussion of their productions to the reading public. This epistolographic material is in the custody of the Murilo Mendes Art Museum - MAMM, administered by the Federal University of Juiz de Fora (UFJF), in Minas Gerais, deposited in the Alencar Family Collection, in the archival fund of the holder Gilberto de Alencar.

Keywords. Mário Matos; Gilberto de Alencar; memory; correspondence 
Tiro uma carta de seu envelope para lê-la com um leve sentimento de profanação como se estivesse me introduzindo em uma correspondência que não me tivesse sido destinada.

Antoine Compagnon

O objetivo é compreender a memória como patrimônio da cultura, isto é, a compreensão das memórias na história da formação do homem enquanto ser histórico, social e, ao mesmo tempo, individuo particular.

Henri Bergson

A complexa relação entre os homens e seus documentos - no caso, as cartas é discutida por Philippe Artières ${ }^{1}$ em artigo intitulado Arquivar a própria vida. Para o autor, o anormal é o sem-papéis, perigoso é o homem que escapa do controle gráfico e, ainda, para ele, escrever cartas significa conservar as lembranças, caracterizando assim a memória materializada. O registro do narrar-se por meio de uma carta e seu conteúdo transforma-se inevitavelmente em arquivo pessoal.

O teórico chama atenção para o fato de que o arquivamento do eu é ao mesmo tempo uma prática de construção de si mesmo e de resistência que implica três aspectos: a injunção social, a prática de arquivamento e a intenção autobiográfica. Portanto, sendo o arquivo um lugar da memória, a escrita epistolar constitui-se efetivamente num ato social memorialístico.

Associado a estas questões parece estar o fascínio pelo segredo que incide sobre a investigação do conteúdo de uma carta. Conceitualmente, "carta" deve ser compreendido como texto escrito em suporte papel, redigido à tinta ou a lápis, que segue para o destinatário dentro de um envelope selado e, devidamente, encaminhado a um correio.

Arquivos pessoais são considerados, dentro da Arquivologia, um ponto crítico devido a sua significativa complexidade decorrente da forma heterogênea de sua acumulação e organização, considerando os diversos tipos de suportes encontrados nesses documentos.

Historicamente, de acordo com $\mathrm{Cook}^{2}$, existe a dificuldade no tratamento de arquivos pessoais. Isso ocorre porque a teoria arquivística clássica, desde o início de sua formação e consolidação, considerou documentos arquivísticos aqueles advindos de uma organização institucional que, segundo os holandeses, considera como "arquivo" um conjunto de documentos escritos, desenhos e material impresso, recebidos ou produzidos oficialmente por algum órgão administrativo ou por um de seus membros, na medida em que tais documentos se destinam a permanecer sob a guarda desse

1 ARTIÉRES, Philippe. “Arquivar a própria vida”. Estudos históricos, 1998.

2 COOK, Terry. "Arquivos pessoais e arquivos institucionais: para um entendimento arquivístico comum da formação da memória em um mundo pós-moderno”. Estudos Históricos, 1998. 
órgão ou de um representante legal da instituição ${ }^{3}$. Ampliando esta premissa, Bellotto esclarece o que é, afinal, “arquivo”, conceito adotado para estas considerações:

\begin{abstract}
[Arquivo é] o conjunto de papéis e material audiovisual ou iconográfico resultante da vida e da obra/ atividade de estadistas, políticos, administradores, líderes de categorias profissionais, cientistas, escritores, artistas etc. Enfim, pessoas cuja maneira de pensar, agir, atuar e viver possa ter algum interesse para as pesquisas nas respectivas áreas onde desenvolveram suas atividades; ou ainda, pessoas detentoras de informações inéditas em seus documentos que, se divulgadas na comunidade científica e na sociedade civil, trarão fatos novos para as ciências, a arte e a sociedade. ${ }^{4}$
\end{abstract}

Algumas pessoas, principalmente os literatos, guardam, por sua vez, outros documentos que consideram ter fundamental importância para a construção da memória cultural de um país e de um povo: junto às cartas, estão os diários, as fotografias, os manuscritos autógrafos e/ou datiloscritos de obras literárias e cópias tipográficas, por exemplo.

Com a intenção de preservar tais itens, locais como arquivos, bibliotecas e museus começaram a constatar a importância da salvaguarda desta documentação visando à preservação da memória social. Esses lugares de memória garantem, assim, a perpetuação desses agentes no cenário nacional. Esta é a missão do Museu de Arte Murilo Mendes (MAMM) administrado pela Universidade Federal de Juiz de Fora (UFJF), em Juiz de Fora, Minas Gerais, no que consiste à guarda e à preservação dos acervos que abriga.

Gilberto Napoleão Augusto de Alencar nasceu em João Gomes (atual Santos Dumont) em $1^{\circ}$ de dezembro de 1886 e faleceu em 04 de fevereiro de 1961. Após estabelecer residência em Juiz de Fora, permaneceu nesta cidade por toda a sua vida. Atuou principalmente como jornalista, tendo chegado a comemorar seu cinquentenário de profissão. Foi, também, membro da Academia Mineira de Letras.

Mário Gonçalves de Matos nasceu em 23 de setembro de 1891 em Santana do Rio São João Acima (atual Itaúna) e faleceu em 29 de dezembro de 1966, em Belo Horizonte. Ao longo de sua vida, fez parte do contexto político brasileiro em distintas ocasiões, tendo chegado a ser deputado federal. Foi um nome marcante na Academia Mineira de Letras, a qual presidiu por três mandatos. Atuou, ainda, como professor e como advogado. Em sua vida pessoal, foi casado duas vezes, teve filhos e dedicou-se a eles tanto quanto ao trabalho. Aliás, seu comprometimento como escritor era observado pela família e constatado orgulhosamente: 
"sempre me impressionou a vocação de escritor de meu pai. [...] a sua pessoa tôda inteira se jogava nessa marca $[\ldots]$ por uma exigência $[\ldots]$ penosa de fidelidade, $[\ldots]$ de incômoda insatisfação de autor que alimenta a certeza de uma obra-prima e não sabe se terá fôrça $[\ldots]$ ou tempo para realizá-la" ${ }^{2}$.

Mário Matos foi apresentado à imprensa ainda muito novo: segundo consta no artigo Reminiscências de Juiz de Fora ${ }^{6}$, o amigo de infância Gilberto de Alencar, em 1912, abriu-lhe as portas d'O Pharol, importante jornal da Juiz de Fora daquele tempo. Embora não seja este o foco da presente pesquisa, é pertinente destacar que falar de ambos os literatos sem mencionar a relevância do jornalismo em suas vidas é tarefa impossível: isso porque tanto Matos quanto Alencar dedicaram muitos de seus anos a maior parte deles, na verdade - à escrita no jornal. É esta, com certeza, a sua maior produção. Publicaram livros também e, a partir de sua leitura, é possível perceber a influência recebida: a forma simples e corrente de escrita, a facilidade de exposição, a finura com que examinavam e desenvolviam os assuntos sem dúvida foram habilidades advindas da lida na imprensa.

É importante manter os acervos de escritores para se recordar e rever o passado a fim de preparar o futuro, mas, sobretudo, para confirmar e firmar sua existência no cotidiano. A importância das cartas não está apenas em explicar e orientar o leitor com revelações biobibliográficas, mas também em apresentar riqueza de ideias e elaborações estéticas, projetos e intimidades do pensamento de literatos que foram expressões importantes na formação da literatura brasileira - embora sejam vozes esquecidas de Minas, como é o caso dos correspondentes em questão.

Em se tratando de correspondência, os conteúdos nelas registrados ajudam a compreender a vida e o momento histórico em que atuaram os signatários; todavia, quando se trata de missivas trocadas entre literatos, o que se pode encontrar vai muito além de declarações da vida pessoal e íntima dos correspondentes e de terceiros por eles citados.

Nas cartas, podem ser localizadas, dentre outras anotações, discussões sobre comportamentos do mercado editorial, sobre ideologias que envolvam a censura atribuída a determinados textos (principalmente os publicados em jornais) e sobre processo de criação. No lote de cartas em questão, é possível observar fragmentos relacionados a alguns destes itens levantados. Observou-se, por exemplo, que Gilberto de Alencar não podia escrever tanto quanto desejava nos periódicos para os quais se dedicava. Ao redigir uma novela para a revista mineira Alterosa, deparou-se com adversidades. Seu texto, tão comentado em várias missivas trocadas, limitava-se a um

5 MATOS, Marco Aurélio. “Meu pai, meu pai!”. Suplemento Literário do Minas Gerais, 1967, p. 3.

6 ALENCAR, Gilberto de. "Reminiscências de Juiz de Fora”. Ilustração Brasileira, 1950, p. 32. 
determinado número de páginas, e, tendo ultrapassado - conforme se comprovou com buscas na referida fonte primária -, precisou ser dividido, a contragosto, em outras edições do periódico: "Também penso como Você quanto à bipartição da novela. Isto mesmo disse ao Miranda, que concordou. Mas é que desejávamos satisfazer a Você e estamos lutando com a angústia de espaço" . Outro fato curioso que se pôde verificar refere-se ao processo de criação: tanto Gilberto de Alencar quanto Mário Matos abordaram em suas epístolas algumas de suas produções, principalmente as que estavam em desenvolvimento. Ambos chegaram a pedir sugestões imparciais sobre seus escritos - como em: "Se o tentar o meu conselho, só lhe peço não esquecer que a atmosfera do conto é a tensão poética. Aprendi tal verdade com o Carlos Drummond"8 -, o que provavelmente contribuiu tanto para o crescimento individual enquanto escritores quanto para a consequência de terem dado ouvido às opiniões: a publicação.

A carta, nesse caso, é vista como paratexto. ${ }^{9}$ Segundo a Crítica Genética e sob esta perspectiva - do estudo da literatura a partir das fontes primárias -, exige uma reorganização, um novo olhar sob o lugar ocupado pela historiografia literária.

Adalberto de Oliveira Souza ${ }^{10}$ nos explica que esta teoria trata da preocupação com os textos inéditos, com a correspondência dos escritores e com a história da obra em si mesma.Épossívelafirmarque,pelofatodeelasempreseocupardoestudodosmanuscritos, dedica-se, também, às memórias do escritor. Assim sendo, pode-se dizer que o objeto da Crítica Genética consiste em " [...] avaliar a criação do autor, os diversos momentos da criação, o como e o porquê da criação" ${ }^{11}$ registrados também na correspondência.

A teórica Cecília Almeida Salles dialoga com esta premissa ao afirmar que:

\begin{abstract}
a tarefa da Crítica Genética é retirar, da materialidade dos documentos [no caso, da carta], a construção intelectual que guarda, isto é, cada fragmento dos documentos é uma peça de uma rede de caráter intelectual, na medida em que cada fragmento foi elaborado pelo [...] [escritor] para a construção de sua obra. O [...] [escritor], sob essa perspectiva, cria seus próprios instrumentos para a construção intelectual que envolve o ato criador. Tudo tem exatamente a mesma relevância para o crítico genético: um tempo de verbo modificado, uma influência detectada, um pincel adaptado, um pequeno apontamento do ator na rubrica do dramaturgo. ${ }^{12}$
\end{abstract}

7 MATOS, Mário. [carta], 1946.

8 Idem, [carta], 1954.

9 GALVÃO, Walnice Nogueira. "A margem da carta”. Teresa, 2008.

10 SOUZA, Adalberto de Oliveira. "Crítica genética". Teoria Literária: abordagens históricas e tendências contemporâneas, 2009, p. 287.

11 Ibidem, p. 289.

12 SALLES, Cecília Almeida. Crítica genética: fundamentos dos estudos genéticos sobre o processo de criação artística, 2008, p. 58. 
Assim, a Crítica Genética procura interpretar os resultados da decifração dos manuscritos, tendo como finalidade a reconstrução da história do nascimento de um texto, "tentando encontrar os segredos da fabricação de uma obra" ${ }^{13}$ desde os primeiros registros. Oliveira ${ }^{14}$ elucida tratar-se de uma abordagem nova, que teve origem no século XIX e só ganhou destaque no final do século XX, tendo sido introduzida no Brasil apenas em meados da década de 1980.

Ao se dissertar sobre correspondência, além de se pensar sobre os direitos constitucionais a respeito desse documento, por vezes, tão pessoal, cabe apontar alguns questionamentos relevantes, já que, a partir de sua leitura, diversas dúvidas acabam por ser levantadas. É possível delinear, de fato, o perfil dos signatários? Até que ponto os temas abordados são verídicos e em que medida a importância da veracidade dos fatos é relevante na produção literária dos envolvidos no carteado? Santos ${ }^{15}$ afirma que em muitas correspondências os fantasmas ganham rosto, as máscaras caem, as influências se revelam, as dominações se explicam. Exemplo disso é verificado na epístola em que Mário Matos demonstra desagrado com o fato de Alencar assuntar incessantemente a questão do envelhecimento: "E um favor lhe peço, Gilberto. Não me fale mais em velhice em suas cartas. Ando danado da vida com esta fatalidade de envelhecer"16. De fato, revelando-se um discurso sem máscaras, a missiva desnuda o autor e traz à tona seus mais íntimos medos, anseios e inseguranças, o que é observado também nesta revelação: "Estou com um livro de contos pronto, mas, não sei, não acredito que sejam bons. Estou incerto quanto a sua edição" ${ }^{17}$. Ao se confidenciarem, os signatários criam uma documentação de suas vivências, que pode ser advinda de um discurso natural e desinteressado ou repleto de intencionalidade.

Contudo, ainda que exista essa fronteira tênue entre o real e o ficcional nestes textos, não se deve desconsiderar o fato de que, muitas vezes, os eventos narrados realmente ocorreram na vida dos correspondentes, podendo, ainda, se validarem por meio de jornais, revistas e demais periódicos datados da época de escrita da missiva na qual determinados fatos históricos teriam ocorrido. A respeito disso, Santos declara:

Se o texto romanesco trapaceia maravilhosamente com o leitor, jogando ações e sentimentos de personagens irreais, a correspondência, ao contrário,

13 SOUZA, Adalberto de Oliveira. "Crítica genética". Teoria Literária: abordagens históricas e tendências contemporâneas, 2009. p. 292.

14 Ibidem, p. 289-297.

15 SANTOS, Matildes Demétrio dos. Ao sol carta é farol: A correspondência de Mário de Andrade e outros missivistas, 1998.

16 MATOS, Mário. [carta], 1956.

17 Idem, [carta], 1946. 
impõe-se como um discurso sem máscaras. O tempo é palpável. Os fatos e os pormenores do conteúdo podem ser historicamente identificados. ${ }^{18}$

Em vista disso, deve-se teorizar a respeito do autor. Quem é este autor que se expõe na carta? Santos ${ }^{19}$ afirma que "ler uma correspondência não significa conhecer um autor como ele de fato foi mas formar uma imagem acrescida de outros tons e enriquecida por certos ângulos". Pelo caráter íntimo das epístolas, os carteadores, de fato, desnudam-se em seus escritos de diferentes maneiras. Um simples ato de demonstrar preocupação ou de revelar segredos confere à correspondência um certo grau de confiabilidade, como ressalta o literato Mário Matos:

\footnotetext{
O que pode haver [de] instrutivo na correspondência particular dos escritores é o elemento confessional, a parte autobiográfica. Por ser espécie de conversa escrita, travada de amigo a amigo, na maior intimidade, a carta tem, por isso mesmo, feição documentativa. É depoimento sem subterfúgio. ${ }^{20}$
}

Essa característica reveladora da missiva abre discussão para a questão da exposição tanto do correspondente ativo quanto do passivo e, também, de possíveis terceiros mencionados nela, uma vez que a carta não só diz do remetente, como abre espaços para o conhecimento do destinatário, muitas vezes expondo-o por meio de observações e comentários elogiosos ou críticos por parte daquele que escreve. ${ }^{21}$

Deve-se enfatizar que como o senhor do texto é aquele que o escreve e que, portanto, seleciona não só a temática, mas também a forma de abordá-la, ele é o responsável por garantir a verossimilhança nas partes que se ficcionaliza.

Uma outra questão importante a ser abordada com relação ao estudo das cartas é a sua estreita ligação com a memória, já que as descrições dos acontecimentos históricos e pessoais constados nas correspondências são expostas pela ótica do escritor da carta muitas vezes em caráter memorialístico, que pode estar, de fato, recordando eventos passados ou se utilizando, mesmo que inconscientemente, da natureza seletiva da memória para preencher lacunas deixadas pelo esquecimento. Pedro Nava, em seu Balão cativo, argumenta:

18 SANTOS, Matildes Demétrio dos. Ao sol carta é farol: A correspondência de Mário de Andrade e outros missivistas, 1998, p. 21.

19 Ibidem, p. 287.

20 MATOS, Mário. Machado de Assis: o homem e a obra - Os personagens explicam o autor, 1939, p. 363.

21 SANTOS, Matildes Demétrio dos. Ao sol carta é farol: A correspondência de Mário de Andrade e outros missivistas, 1998. 
Para quem escreve memórias, onde acaba a lembrança, onde começa a ficção? Talvez sejam inseparáveis. Os fatos da realidade são como pedra, tijolo - argamassados, virados parede, casa, pelo saibro, pela cal, pelo reboco da verossimilhança - manipulados pela imaginação criadora. (...). Só há dignidade na recriação. O resto é relatório. ${ }^{22}$

Eliane Vasconcellos esclarece que os pesquisadores desse tipo de manuscrito têm se conscientizado de que podem se deparar com elementos de significativa relevância ao analisá-los, uma vez que estes escritos funcionam como "testemunho vivo de uma época" 23 , podendo registrar vivências pessoais, situações cotidianas, ações, reflexões e confidências, ou seja, trata-se da manifestação da memória como registro vivido, como preservação, por exemplo, de um fato histórico e resgate de imagens ou reconstrução da experiência humana. Mário Matos, em uma de suas cartas direcionadas a Gilberto de Alencar, aceita, com entusiasmo, a sugestão de seu correspondente para a criação de um monumento em homenagem ao poeta Belmiro Braga, deixando, nestas páginas, documentado este momento histórico antes mesmo de ele ocorrer: "Estou pronto a auxiliar, no que me for possível, a realização da ideia de erguer-se um monumento ao nosso inolvidável Belmiro" ${ }^{24}$. Acrescenta-se que, em carta posterior, Matos confirma que houve a referida inauguração desse monumento que, contribuindo para a preservação da memória, até hoje encontra-se erguido no centro do Parque Halfeld, situado em Juiz de Fora.

Segundo Santo Agostinho, a memória é fundamentalmente um lugar de encontro e afirmação de si mesmo onde se buscam as causas da vida presente. E completa essa definição:

Tudo isto realizo interiormente, no imenso palácio de minha memória. Ali eu tenho às minhas ordens o céu, a terra, o mar, com todas as sensações que neles pude perceber, com exceção das de que já me esqueci. Ali me encontro comigo mesmo, e me recordo de mim e de minhas ações, de seu tempo e lugar do estado de espírito em que estava, e dos sentimentos que me dominavam quando as praticava. ${ }^{25}$

Uma das maneiras que se tem de registrar os tempos e os sentimentos vividos é colocando suas impressões em suporte papel - como a carta, por exemplo. É justamente pelo fato de serem documentos que podem conter os mais diversos

22 NAVA, Pedro. Balão cativo, 1977, p. 288.

23 VASCONCELLOS, Eliane. "Carta missiva”. Remate de Males, 1998, p. 61.

24 MATOS, Mário. [carta], 1939.

25 SANTO AGOSTINHO. As confissões, entre 397 e 401.d.C., p. 184. 
temas ali inseridos: seu caráter pessoal invariavelmente contribui para que ela se torne um arquivo memorialístico (independentemente de tratar-se da individualidade ou da coletividade).

É neste sentido memorialístico que podemos associar a carta como fonte histórica. Para tal, José D’Assunção Barros ${ }^{26}$ assim explica o significado das fontes históricas no texto de mesmo nome:

Fonte histórica [...] é tudo aquilo que produzido pelo homem ou trazendo vestígios de sua interferência pode nos proporcionar um acesso à compreensão do passado humano. [...] são fontes históricas [...] documentos textuais [...] como também quaisquer outros que possam nos oferecer um testemunho ou um discurso proveniente do passado humano, da realidade um dia vivida e que se apresenta como relevante [para a pesquisa, como a correspondência]. ${ }^{27}$

Ao se corresponder, o indivíduo acaba, mesmo que não intencionalmente, gerando um arquivo de si mesmo. Todos os fatos narrados e até mesmo o ponto de vista do autor das missivas podem e devem ser tratados como fontes históricas dos eventos e/ou acontecimentos pertinentes à época vivida por ele. Por meio do estudo e da análise epistolográfica, pode-se compreender de forma mais detalhada e pessoal as opiniões do autor, seus gostos, seus métodos de escrita, suas inspirações, suas angústias, tristezas, decepções e alegrias.

Finalizando, entendemos que a correspondência de um escritor nos possibilita um novo modo de olhar o cenário literário da época. Desta forma, em acervos epistolográficos à espera do olhar entusiasmado de um pesquisador, acumulam-se documentos fundamentais para a (trans)formação da historiografia literária.

Nesse sentido, importa ressaltar que, antigamente, não era dada tanta importância aos documentos pessoais, os quais eram vistos somente como objetos de interesse do produtor e de seus familiares. Os arquivos públicos já interessavam as civilizações desde séculos passados, pois eram indispensáveis para garantir direitos e privilégios detentores de um valor cultural intrínseco. Além disso, havia e há um certo preconceito em relação aos arquivos pessoais porque muitos teóricos duvidavam e duvidam da imparcialidade destes em comparação com a neutralidade (?) dos arquivos públicos.

26 BARROS, José D’Assunção. “Fontes históricas: revisitando alguns aspectos primordiais para a pesquisa histórica”. Mouseion, 2012.

27 Ibidem, p. 130. 
Posteriormente, esse pensamento se mostrou defasado, principalmente devido ao advento dos princípios pós-modernistas. Conclui-se, então, que os arquivos pessoais estão muito mais próximos dos arquivos públicos do que se pode considerar. Ambos são reflexos de uma construção intencional e são carregados de subjetividade. Esses arquivos, públicos e pessoais, apesar de possuírem características distintas, assemelhamse.

A partir dessa realidade, compreender a correspondência como fonte de pesquisa literária legitima a importância tanto dos correspondentes quanto dessa troca epistolar para a devida ocupação do lugar da literatura nos cenários nacional e internacional.

Cada detalhe retratado na correspondência e cada assunto mencionado possibilitam que o leitor adquira uma compreensão do contexto sociocultural referente à época em que se deu a escrita. Isso lhe permite, possivelmente, fazer inferências e elaborar suposições na relação dicotômica que se estabelece entre o real x ficcional de cada parte do texto missivístico.

O desafio do nosso trabalho consiste em utilizar esta nova abordagem para avançar na investigação sobre a correspondência de Mário Matos e Gilberto de Alencar. Interessa ressaltar a importância de uma pesquisa, cada vez mais adequada, em suas histórias pessoal e profissional, assim como uma avaliação prévia dos documentos que integram o seu fundo.

Por último, desejamos que esse trabalho permita que novos estudos sejam realizados na área de arquivos pessoais, mais especificamente com a correspondência, pois esse processo ainda se encontra incipiente.

\section{Referências bibliográficas}

ALENCAR, Gilberto de. Reminiscências de Juiz de Fora. Ilustração Brasileira, ano XLI, n. 182, p. 32, jun. 1950.

ARTIÉRES, Philippe. Arquivar a própria vida. Estudos bistóricos. Rio de Janeiro: CPDOC, v. 11, n. 21, 1988, p. 1-216.

BARROS, José D’Assunção. Fontes históricas: revisitando alguns aspectos primordiais para a pesquisa histórica. Mouseion, n. 12, maio/ago. 2012.

BELLOTTO, Heloísa Liberalli. Arquivos permanentes: tratamento documental. 4. ed. Rio de Janeiro: Editora FGV, 2016. 320p. 
BERGSON, Henri. Da sobrevivência das imagens. A memória e o espírito. In: Matéria e memória: ensaio sobre a relação do corpo com o espírito. Tradução Paulo Neves. 4. ed. São Paulo: WMF Martins Fontes, 2010. p. 155-208.

COMPAGNON, Antoine. A era das cartas. Belo Horizonte: UFMG, 2019, p. 25.

COOK, Terry. Arquivos pessoais e arquivos institucionais: para um entendimento arquivístico comum da formação da memória em um mundo pós-moderno. Revista Estudos Históricos, Rio de Janeiro, v. 11, n. 21, 129-149, 1998. Disponível em: http:// bibliotecadigital.fgv.br/ojs/index.php/reh/article/view/2062 Acesso em: 28 abr. 2020.

GALVÃO, Walnice Nogueira. A margem da carta. Teresa. Revista de literatura brasileira. São Paulo: USP, 2008.

MATOS, Marco Aurélio. Meu pai, meu pai! Suplemento Literário do Minas Gerais, Belo Horizonte, ano II, n. 70, p. 3, 30 dez. 1967.

MATOS, Mário. Machado de Assis: o homem e a obra - Os personagens explicam o autor. São Paulo: Companhia Editora Nacional, 1939. (Coleção Brasiliana, $5^{a}$ série da Biblioteca Pedagógica Brasileira, vol. 153).

MATOS, Mário. [carta] 09 maio 1939, Belo Horizonte [para] ALENCAR, G. Juiz de Fora. 2f.

MATOS, Mário. [carta] 12 maio 1946, Belo Horizonte [para] ALENCAR, G. Juiz de Fora. 1f.

MATOS, Mário.[carta] 21 mar. 1954, Belo Horizonte [para] ALENCAR, G. Juiz de Fora. $4 \mathrm{f}$.

MATOS, Mário. [carta] 12 nov. 1956, Belo Horizonte [para] ALENCAR, G. Juiz de Fora. $4 \mathrm{f}$.

MULLER, S.; FEITH, J. A.; FRUIN, R. Manual de arranjo e descrição de arquivos. 2. ed. Rio de Janeiro: Arquivo Nacional. 1973. 136p.

NAVA, Pedro. Balão cativo. Rio de Janeiro: J. Olympio, 1977. 
POLLAK, Michael. Memória e identidade social. In: Estudos históricos, Rio de Janeiro, v. 5 , n. 10,1992 . p. $200-212$.

SALLES, Cecília Almeida. Crítica genética: fundamentos dos estudos genéticos sobre o processo de criação artística. 3 ed. São Paulo: EDUC, 2008.

SANTO AGOSTINHO. As confissões. Tradução. Frederico Ozanam Pessoa de Barros. Rio de Janeiro: Ediouro (Coleção Universidade de Bolso, v. 3. 1993), [entre 397 e 401.d.C].

SANTOS, Matildes Demétrio dos. Ao sol carta é farol: A correspondência de Mário de Andrade e outros missivistas. São Paulo: Annablume, 1998.

SOUZA, Adalberto de Oliveira. Crítica genética. In: BONNICI, T.; ZOLIN, L.O. (Org.). Teoria Literária: abordagens históricas e tendências contemporâneas. 3 ed. Maringá: EDUEM, 2009. p. 287-300.

VASCONCELLOS, Eliane. Carta missiva. Remate de Males. Campinas: UNICAMP, v. 18, p. 61-70, 1998. Disponível em: https://periodicos.sbu.unicamp.br/ojs/index.php/ remate/article/view/8636136. Acesso em: 08 maio 2020.

Submissão: $18 / 02 / 2020$

Aceite: $29 / 05 / 2020$

https://doi.org/10.5007/2176-8552.2021.e73712

Esta obra foi licenciada com uma Licença Creative Commons Atribuição-NãoComercial 4.0 Internacional. 